\title{
ANALISA VALUASI EKONOMI EKOWISATA MANGROVE DI PANTAI MAYANGAN SELAT MADURA
}

\author{
Mimit Primyastanto* \\ Fakultas Perikanan dan Ilmu Kelautan, Universitas Brawijaya, \\ J1. Veteran Malang 65145, Jawa Timur, Indoneia \\ *Koresponden penulis : mimitp@ub.ac.id
}

\begin{abstract}
Abstrak
Dalam Rancangan Pembangunan Jangka Menengah Daerah (RPJMD) tahun 2006, Kota Probolinggo mencanangkan untuk membangun sektor ekowisata berbasis wisata bahari dan pantai dan pada tahun 2012 investor PT. Bee Jay Bakau Resort mmewujudkan proyek dari Pemerintah Kota Probolinggo. Daerah muara kali banger yang dulunya merupakan daerah kumuh dan penuh sampah kini disulap menjadi sebuah daerah yang bernilai ekonomi serta menarik wisatawan baik domestik maupun mancanegara. Dengan adanya ekowisata ini diharapkan tidak hanya memberi manfaat berupa pendapatan asli daerah namun juga dampak sosial dan ekonomi terhadap masyarakat. Tujuan dari penelitian ini adalah mengidentifikasi profil ekowisata konservasi hutan mangrove, Menganalisa Valuasi Ekonomi yang telah dilakukan pada ekowisata konservasi hutan mangrove dan menganalisis dampak positif sosial dan ekonomi yang didapat oleh masyarakat pesisir Selat Madura. Jenis penelitian yang digunakan yaitu jenis penelitian kualitatif dengan menggunakan teknik penentuan narasumber non-probability dengan metode purposive. Hasil penelitian ini diketahui bahwa ekowisata konservasi mangrove ini didirikan oleh Investor PT. Bee Jay Bakau Resortproject (BJBR) diatas lahan 8,9 Ha milik Pemerintah Kota Probolinggo, didapatkan modal investasi sebesar Rp.507.000.000 dengan modal tetap Rp.520.442.00 dan modal lancar Rp.147.000.000. Kemudian biaya total Rp.667.642.000. Penerimaan Rp.960.000.000. Nilai Valuasi Ekonomi dengan Model Total Economic Value adalah TEV = DUV + IUV + OV + BV = Rp. 13.908.860.034.000,-. Dampak Sosial yang dirasakan masyarakat pesisir yakni berupa tingkat pengangguran yang berkurang, serta indeks kesehatan masyarakat yang meningkat. Dampak ekonomi yang dirasakan masyarakat berupa peningkatan pendapatan, penduduk miskin berkurang.
\end{abstract}

Kata kunci: Valuasi ekonomi, ekowisata, mangrove, social ekonomi

\begin{abstract}
In the design midterm regional development (DMRD/RPJMD) in 2006, Probolinggo city launched to build ecotourism based sector maritime tourism dan the coast dan in 2012 investors PT. Bee Jay Bakau Resortproject make of municipal goverment Probolinggo. Banger river estuary that which once a the slum and full of dross now transformed into a region economy value as well as attract tourist both domestic and foreign. By the presence of this ecotourism is expected to not only give benefits in the form of local revenue but also economic and social impact on the coastal community. The purpose of this research is to identify the profile of ecotourism mangrove forest conservation, analyze Economic Valuation that was done on ecotourism mangrove forest conservation and analyze the impact of social and economic obtained by coastal community at Madura Strait. The kind of this research used that is the kind of qualitative research using a technique the determination of speakers non-probablity with methods purposive. The result of this research can be seen that ecotourism conservation it was built by investors PT. Bee Jay Bakau Resortproject (BJBR) in 8,9 Hectare belonging to the Probolinggo city goverment. Capital investment abput Rp.507.000.000 with fixed capital Rp.520.442.000 and capital smoothly Rp.147.000.000 and for the total Rp.667.642.000. Rp.960.000.000 revenue. Analysis of Valuation Economic with Total Economic Value (TEV) Models $: T E V=D U V+I U V+O V+B V=R p .13 .908 .860 .034 .000,-$. The social impact felt rhe coastal communities namely of unemployment rate had beed cut, and index community health that rises. Economic impact felt by community of the increase in income, and poor people reduced.
\end{abstract}

Keyword: Economic Valuation, Ecotourism, Mangrove ,Socio-Economic 


\section{PENDAHULUAN}

Telah nampak kerusakan didarat dan dilaut disebabkan perbuatan tangan manusia, supaya Allah merasakan kepada mereka sebahagian dari (akibat) perbuatan mereka, agar mereka kembali (kejalan yang benar) (Q.S. AR-RUUM : 41). [11]

Valuasi ekonomi dapat digunakan untuk mentransformasi nilai ekologis ekosistem mangrove menjadi nilai ekonomi dengan mengukur nilai moneter dari seluruh barang dan jasa yang dihasilkan [6]

Ekowisata dapat didefinisikan sebagai suatu konsep pengembangan pariwisata berkelanjutan yang bertujuan untuk mendukung upaya-upaya pelestarian lingkungan (alam dan budaya). Dan meningkatkan partisipasi masyarakat dalam pengelolaan, sehingga memberikan manfaat ekonomi kepada masyarakat setempat. Sementara ditinjau dari segi pengelolaannya, ekowisata dapat didefinisikan sebagai penyelenggaraan kegiatan wisata yang bertanggung jawab di tempat-tempat alami dan atau daerah-daerah yang dibuat berdasarkan kaidah alam dan secara ekonomi berkelanjutan yang mendukung upaya-upaya pelestarian lingkungan. Ekowisata sangat tepat dan berdayaguna dalam mempertahankan keutuhan dan keaslian ekosistem di area yang masih alami. Bahkan dengan ekowisata pelestarian alam dapat ditingkatkan dalam segi kualitasnya [7]

Hutan mangrove merupakan suatu tipe hutan yang tumbuh didaerah pasang surut, terutama dipantai yang terlindung, laguna, atau muara sungai yang tergenang pasang dan bebas dari genangan pada saat surut yang komunitas tumbuhannya bertoleransi terhadap garam. Fungsi istimewa hutan mangrove secara ekologis ialah sebagai penahan ombak, sehingga dapat mencegah terjadinya abrasi pantai dan penyerap limbah yang ada diperiaran sehingga dapat mengurangi pencemaran. Disamping itu, hutan mangrove menjadi tempat memijah berbagai biota peraran, seperti ikan, udang, dan kerang-kerangan [19]

Penerapan Undang-Undang No. 32
Tahun 2004 tentang Pemerintah Daerah membawa konsekuensi pada kabupaten dan/atau kota sebagai basis penyelenggaraa otonomi daerah. Pertama, daerah kabupaten/kota dituntut untuk lebih mampu menjalankan roda pemerintahan secara mandiri. Untuk itu pemerintah daerah harus mampu menggali potensi lokal guna meningkatkan pendapatan asli daerah. Kedua, otonomi daerah harus mampu mendorong masyarakat untuk lebih berpartisipasi dalam berbagai aspek kehidupan masyarakat pesisir [16].

Tujuan penelitian ada 3 , yaitu mengetahui dan menganalisa : (1)Profil Ekoswisata BJBR. (2) Nilai Valuasi Ekonomi dan (3) Dampak Positif Sosial Ekonomi dari Ekowisata BJBR.

\section{METODE PENELITIAN}

Penelitian dengan judul Analisa Valuasi Ekonomi Ekowisata Mangrove di Pantai Mayangan, Selat Madura ini dilaksanakan pada bulan Maret 2018 hingga Agustus 2018 yang terletak di Pantai Mayangan, Selat Madura.

\section{Jenis Penelitian}

Jenis penelitian yang digunakan dalam penelitian ini adalah jenis penelitian kualitatif. dengan mengguakan data kuantitatif skala kecil. Alasan penggunaan jenis penelitian kualitatif dalam penelitian ini dikarenakan peneliti berlaku sebagai instrumen penelitian yang mana peneliti harus interaktif dengan responden guna mendapatkan data baik data primer maupun sekunder [4].

\section{Jenis Data}

Data yang digunakan yaitu kuantitatif dan kualitatif. Data kuantitatif yang digunakan berupa data mengenai investasi jangka pendek meliputi permodalan, biaya total, penerimaan, $\mathrm{R} / \mathrm{C}$ ratio, keuntungan, BEP dan rentabilitas. Kemudian data kualitatif yang digunakan berupa data dampak sosial dan ekonomi yang diterima masyarakat, maupun data dampak mangrove baik secara langsung dan tidak langsung. 


\section{Sumber Data}

\section{Data Primer}

Data primer didapatkan dari wawancara, observasi dan kuisioner. Wawancara dalam penelitian ini yang menjadi narasumber adalah pihak pengelola ekowisata BJBR, staf DKP Kota Probolingo serta masyarakat sekitar ekowisata mangrove tersebut yang memanfaatkan kehadiran ekowisata guna mendapatkan penghasilan. Observasi dalam penelitian ini dilakukan pengamatan yang meliputi aktifitas masyarakat yang berada pada area ekowisata, keadaan umum ekowisata maupun kondisi mangrove. Kuisioner dalam penelitian ini yang menjadi responden adalah masyarakat yang memiliki mata pencaharian di sekitar ekowisata konservasi mangrove [4].

\section{Data Sekunder}

Data sekunder dalam penelitaian ini berasal dari beberapa sumber diantaranya adalah Memorandum of Understanding (MoU) ekowisata BJBR yang berasal dari Dinas Kelautan Perikanan Kota Probolinggo dan Kantor Ekowisata Hutan Mangrove BJBR, data Badan Pusat Statistik Kota Probolinggo serta data lain yang bersumber dari penelitian terdahulu.

\section{Analisa Data}

Analisa data pada penelitian ini dilakukan dengan analisa data kualitatif. Data dalam penelitian kualitatif didapatkan dari berbagai sumber yang pada umumnya berupa data kualitatif walaupun terdapat juga data kuantitatif. Sehingga teknik analisis data belum ada polanya dengan jelas [19]. Dalam melakukan analisa data terdapat beberapa metode digunakan antara lain:

1. Profil Ekowisata Mangrove

2. Total Economic Value (TEV) Ekowisata Mangrove (Haslinah et al. 2012)

$$
\mathrm{TEV}=\mathrm{DUV}+\mathrm{IUV}+\mathrm{OV}+\mathrm{BV}
$$

Keterangan :

TEV: Total Economic Value

DUV : Direct Use Value

IUV : Indirect Use Value

OV : Option Value
BV : Bequest Value

\section{Permodalan}

Modal dibagi menurut asalnya yaitu modal sendiri dan modal asing. Modal sendiri merupakan modal yang berasal dari pemilik usaha atau perusahaan, yang ditanamkan kedalam perusahaan dalam waktu yang lamanya tak tentu atau tak dapat dipastikan. Sedangkan modal asing merupakan modal yang berasal dari luar perusahaan yang memiliki sifat yang sementara bekerja didalam suatu perusahaan yang bersangkutan. Modal asing tersebut daoat berupa hutang perusahaan yang harus dikembalikan dikemudian hari [18].

\section{Biaya Produksi}

Biaya dapat diklasifikasikan menjadi dua yaitu biaya tetap (fixed cost) dan biaya tidak tetap (variable cost). Biaya tetap besarannya tidak tergantung kepada besar kecil atau banyak sedikit produksi yang dihasilkan. Semakin besar jumlah produksi yang dihasilkan maka biaya variabelnya otomatis akan besar. Sebaliknya apabila jumlah produksi sedikit/kecil maka biaya variabelnya juga akan kecil [12].

$\mathrm{TC}=\mathrm{FC}+\mathrm{VC}$

$\mathrm{TC}$ : biaya total $(\mathrm{Rp})$

FC : biaya tetap (Rp)

$\mathrm{VC}$ : biaya variabel $(\mathrm{Rp})$

\section{Penerimaan}

Penerimaan (Total Revenue) merupakan pendapatan kotor yang dihasilkan dari kegiatan produksi yang dijalankan oleh suatu perusahaan yang dapat didefinisikan sebagai nilai produk total dari usaha dalam kurun waktu tertentu. Penerimaan didapatkan dari penjualan produk akhir dalam bentuk uang [13].

\section{Revenue Cost ratio ( $R / C$ ratio $)$}

Analisa $\mathrm{R} / \mathrm{C}$ ratio merupakan suatu alat analisis yang berfungsi dalam melihat keuntungan relatif dalam suatu usaha yang dilakukan dalam kurun waktu 1 tahun 
terhadap biaya yang digunakan dalam kegiatan produksi yang dilakukan. Suatu usaha dapat dikatakan layak untuk dijalankan apabila memiliki $\mathrm{R} / \mathrm{C}$ ratio lebih besar daripada $1(\mathrm{R} / \mathrm{C}>1)$. Hal ini berarti bahwa semakin tinggi nilai $\mathrm{R} / \mathrm{C}$, ratio maka semakin menunjukan bahwa kegiata usaha yang dilakukan semakin memberikan keuntungan yang besar [15].

$\mathrm{R} / \mathrm{C}$ Ratio $=\frac{T R}{T C}$

Keterangan :

$\mathrm{R} / \mathrm{C}$ : Return Cost

TR : Penerimaan Total (Total Revenue)

TC : Biaya Total (Total Cost)

Dengan kriteria keputusan sebagai berikut

R/C Ratio > 1 : Usaha menguntungkan

$\mathrm{R} / \mathrm{C}$ Ratio $=1$ : Usaha impas (tidak untung

dan tidak rugi)

$\mathrm{R} / \mathrm{C}$ Ratio $<1 \quad$ : Usaha rugi

Keuntungan

Keuntungan merupakan pendapatan bersih dari suatu kegiatan usaha yag dilakukan sehingga dapat diartikan sebagai besaran dari penerimaan setelah dikurangi dengan berbagai biaya yang dikeluarkan untuk proses produksi tetap maupun tidak tetap [14].

Analisa perhitungan keuntungan $(\pi)$ dala, satu tahun.

a. Keuntungan ( $\pi$ ) sebelum zakat (Earning

Before Zakat)

$\mathrm{EBZ}=\mathrm{TR}-\mathrm{TC}$

Keterangan :

$\pi \quad:$ Keuntungan (Rp)

TR : Total Revenue/Penerimaan total (Rp)

TC : Total Cost/Biaya total (Rp)

b. Keuntungan ( $\pi$ ) setelah zakat ( Earning After Zakat )

Zakat $(Z)=2,5 \% \times$ EBZ

$\mathrm{EAZ}=\mathrm{EBZ}-\mathrm{Z}$
Break Event Point (BEP)

Break Event Point (BEP) merupakan suatu nilai dimana hasil penjualan produksi sama dengan biaya produksi, sehingga pengeluaran sama dengan pendapatan. Dengan demikian pada saat itu pengusaha mengalami impas, tidak untung dan tidak rugi. Berdasarkan perhitungannya, BEP dibagi menjadi dua, yaitu BEP atas dasar sales dan BEP atas dasar unit [17].

a. BEP atas dasar sales

$$
\begin{gathered}
\text { BEP sales }= \\
\text { FC } \\
1-\frac{\text { VC }}{\text { Total Penjualan }}
\end{gathered}
$$

Keterangan :

$\mathrm{FC}$ : biaya tetap $(\mathrm{Rp})$

$\mathrm{VC}$ : biaya variabel $(\mathrm{Rp})$

b. $\quad$ BEP atas dasar Unit $=$

$$
\frac{F C}{\text { Price per unit }- \text { VC per unit }}
$$

Keterangan :

FC : biaya tetap $(\mathrm{Rp})$

$\mathrm{VC}$ : biaya variabel $(\mathrm{Rp})$

\section{Rentabilitas}

Rentabilitas suatu perusahaan menunjukan perbandingan antara laba dengan modal penghasil laba tersebut. Rantabilitas merupakan kemampuan perusahaan menghasilkan laba dengan modal yang tersedia dalam periode waktu tertentu [15]. Analisa perhitungan Rentabilitas usaha

Rentabilitas $=\frac{L}{M} \times 100 \%$

Keterangan :

L : Laba (Rp)

M: Modal (Rp) 


\section{HASIL DAN PEMBAHASAN}

\section{Profil Ekowisata Mangrove}

\section{Sejarah Ekowisata}

Bee Jay Bakau Resort terletak di kawasan Pelabuhan Perikanan Pantai Mayangan, Kelurahan Mayangan, Kecamatan Mayangan. Bee Jay Bakau Resort atau yang biasa dikenal dengan BJBR menyediakan ekowisata konservasi mangrove. Selain menyediakan ekowisata konservasi mangrove, tempat wisata ini juga menyediakan beberapa wahana menarik lainnya seperti Rest-O-Tent yakni rumah makan terapung dengan menyajikan pemandangan hutan bakau beserta panorama laut nan indah, Bungalow Keluarga yang memberikan pengalaman seperti berlayar di laut saat pasang laut dan Majengan Bakau Beach yang dilengkapi dengan fasilitas sepeda air, kayak, saung-saung keluarga serta hiasan lampu yang menambah semarak keindahan saat malam hari [3].

Ekowisata ini dirintis oleh Bapak Benjamin Mangitung, Bapak Tan Justinus dan Bapak Juda Mangitung yang tergerak untuk mengubah sampah menjadi emas. Dahulu muara kali banger memang terkenal dengan tempat yang penuh sampah dan berbau menyengat. Hal ini diperparah oleh sifat dan perilaku masyarakat yang kerap membuang sampah di kali yang dulunya memiliki sejarah cukup panjang dalam berdirinya Kota Probolinggo [10].

\section{Keadaan Umum Ekowisata}

Ekowisata Konservasi Hutan Mangrove Bee Jay Bakau Resort atau yang biasa dikenal dengan sebutan BJBR terletak di Kawasan Pelabuhan Perikanan Pantai Mayangan, Kelurahan Mayangan Kecamatan Mayangan, Kota Probolinggo. Ekowisata ini berdiri sejak tahun 2012 di lahan seluas 8,9 Hektar milik Pemerintah Kota Probolinggo. Akses menuju Bee Jay Bakau Resort terbilang cukup mudah, jalan menuju ekowisata berupa jalan aspal yang tentu memudahkan bagi semua jenis kendaraan untuk lewat. Didalam area ekowisata ditata sangat rapi dan menarik, serta beberapa jenis wahana dan area foto guna memanjakan wisatawan.

\section{Visi dan Misi Ekowisata}

Visi yang dimiliki ekowisata ini adalah "Mengubah Sampah Menjadi Emas". Guna menjalan visi tersebut maka dibentuklah visi ekowisata antara lain :

1. Menjadi wahana pendidikan untuk para pelajar, agar mereka mulai belajar mencintai lingkungan sejak dini.

2. Menjadi wahana wisata keluarga yang eksklusif bernuansa pantai pasang surut yang khas dengan keanekaragaman flora dan faunanya.

3. Menjadi wahana penelitian yang terbuka bagi semua orang, baik pelajar, mahasiswa dan peneliti dari dalam dan luar negeri.

\section{Analisa Valuasi Ekonomi}

\section{Nilai DUV (Direct Use Value)}

\section{Permodalan}

Modal dibagi menurut asalnya yaitu modal sendiri dan modal asing. Modal sendiri merupakan modal yang berasal dari pemilik usaha atau perusahaan, yang ditanamkan kedalam perusahaan dalam waktu yang lamanya tak tentu atau tak dapat dipastikan. Sedangkan modal asing merupakan modal yang berasal dari luar perusahaan yang memiliki sifat yang sementara bekerja didalam suatu perusahaan yang bersangkutan. Modal asing tersebut dapat berupa hutang yang dimiliki oleh perusahaan yang harus dikembalikan dikemudian hari [18] .

Aktiva tetap dari ekowisata konservasi mangrove ini sebesar Rp. 507.000.000. Modal investasi yang dikeluarkan untuk ekowisata konservasi mangrove ini terdiri dari Jembatan, Beton Cor penahan jembatan, Pintu masuk dan keluar area mangrove, Genset 50 kVA serta pencahayaan disekeliling konservasi hutan mangrove. Modal tetap yang digunakan untuk ekowisata ini merupakan modal dari PT. BJBR sebesar Rp. 520.442.000, meliputi penyusutan dari invesdtasi, Upah Tenaga Kerja, Pajak Bumi dan Bangunan (PBB), 
sewa lahan 8,9 Hektar dari Pemerintah Kota Probolinggo, dan perawatan seluruh fasilitas yang ada di ekowisata konservasi hutan mangrove.

\section{Biaya Total}

Biaya produksi yang digunakan dalam usaha ekowisata konservasi hutan mangrove ini meliputi biaya tetap (fixed cost) yaitu biaya yang dikeluarkan setiap 1 tahun termasuk biaya didalamnya yaitu biaya penyusutan modal investasi, upah tenaga kerja, Pajak Bumi dan Bangunan (PBB), perawatan fasilitas area mangrove serta sewa lahan sebesar 8,9 Hektar sebesar Rp. 520.442.000, dan biaya variabel (variable cost) yang dikeluarkan selama 1 tahun berupa biaya pembayaran listrik dan lain-lain yang biayanya dapat berubah mengikuti perkembangan biaya umum dalam 1 tahun sebesar Rp. 147.200.000. Sehingga biaya total (total cost) yang harus dikeluarkan oleh ekowisata konservasi mangrove ini tiap 1 tahun sebesar Rp. 667.642.000.

\section{Penerimaan}

Penerimaan yang didapat dari hasil penjualan tiket masuk ke ekowisata konservasi mangrove selama 1 (satu) tahun. Dalam kurun waktu 1 tahun penjualan tiket sebanyak 24.000 lembar tiket dengan harga 1 tiket yakni Rp.40.000. Jadi, penerimaan pada ekowisata konservasi mangrove dalam 1 tahun sebesar Rp. 960.000.000.

\section{Revenue Cost Ratio (R/C Ratio)}

Pada Ekowisata Konservasi Mangrove didapatkan hasil perhitungan Revenue Cost Ratio (R/C Ratio) sebesar 1,438. Dengan demikian dapat dikatakan bahwa ekowisata ini menguntungkan dan layak untuk dilanjutkan, karena nilai $\mathrm{R} / \mathrm{C}$ ratio lebih besar dari $1(\mathrm{R} / \mathrm{C}>1)$ atau dengan kata lain penerimaan yang diterima sebesar 1,44 kali biaya yang dikeluarkan.

\section{Break Even Poin (BEP)}

Pada Ekowisata Konservasi Mangrove ini diperoleh pendapatan dari tiket masuk ke lokasi ekkowisata dalam kurun waktu 1 tahun. Hasil perhitungan BEP sales sebesar Rp.
614.695.276. Dengan kesimpulan, bahwa ekowisata konservasi mangrove ini menguntungkan karena nilai penerimaanya lebih besar dari nilai BEP sales yang diperoleh dari hasil perhitungan.

\section{Keuntungan}

Keuntungan atau pendapatan bersih yang diperoleh dari ekowisata konservasi mangrove selama waktu 1 (satu) tahun sebesar Rp. 292.358.000. Keuntungan tersebut diperoleh total penerimaan sebesar $\mathrm{Rp}$. 960.000.000 dikurangi dengan total biaya sebesar Rp. 667.642.000. Adapun pengeluaran dikurangi zakat sebesar 2,5\% yakni sebesar Rp. 7.308 .950 sehingga penerimaan menjadi 285.049.050,-.

Zakat sebesar Rp. 7.308.950, selayaknya diberikan kepada orang-orang yang membutuhkan sesuai dengan perintah Allah SWT dalam Al Qur'an Surah At Taubah ayat 60: "Sesungguhnya zakat-zakat itu, hanyalah untuk orang-orang fakir, orang-orang miskin, pengurus-pengurus zakat, para mu'allaf yang dibujuk hatinya, untuk (memerdekakan) budak, orang-orang yang berhutang, untuk jalan Allah dan orang-orang yang sedang dalam perjalanan, sebagai sesuatu ketetapan yang diwajibkan Allah; dan Allah Maha Mengetahui lagi Maha Bijaksana “.

\section{Rentabilitas}

Dari perhitungan rentabilitas ekowisata konservasi mangrove diperoleh nilai rentabilitas sebesar 44\%. Dapat disimpulkan bahwa ekowisata konservasi mangrove ini menguntungkan dan layak untuk dilanjutkan. Hal tersebut dikarenakan nilai rentabilitas tersebut lebih besar dari sukuk bunga bank yang berlaku saat ini sebesar $12 \%$ pertahun.

\section{Nilai IUV (Indirect Use Value) Ekowisata Mangrove}

\section{Mangrove Diperbaiki}

Dengan adanya konservasi mangrove hal ini tentu jumlah mangrove yang akan memberikan manfaat kepada masyarakat baik sebagai penahan intrusi air laut, pemecah gelombang maupun pengendali banjir rob. Masyarakat tentu tidak perlu lagi was was bilaman terjadi gelombang tinggi 
sebab ada mangrove yang menjadi green belt atau sabuk hijau di sepanjang Pelabuhan Perikanan Pantai Mayangan, Selat Madura. Bilamana kondisi mangrove semakin banyak dan baik tentu akan memberikan dampak berupa meningkatnya fauna yang dapat dipanen oleh masyarakat seperti halnya tiram Crossaetta [19].

\section{Penyerap $\mathrm{CO} 2$}

Menurut [8], Selain tanggul alami, manfaat tidak langsung lainnya dari adanya hutan mangrove adalah penyerapan $\mathrm{CO} 2$. Jika diketahui luas hutan mangrove 8,9 Hektar atau $89.000 \mathrm{~m}^{2}$ dan dapat menyerap gas $\mathrm{CO} 2$ bebassebesar 0,3670128 t CO2eq setiap meter persegi pertahun dan biaya alat penyerap $\mathrm{CO}_{2}$ yaitu pohon sintesis $\mathrm{Rp}$. 396.000.000 dengan kemampuan penyerapan $\mathrm{CO} 290.000$ t $\mathrm{CO} 2 \mathrm{eq}$ setiap tahunnya yang memiliki umur teknis 10 tahun maka perhitungannya sebagai berikut

$\mathrm{CO} 2=\left(\sum\right.$ luas x 0,3670128 t CO2eq / Jumlah serapan) $x$ Cost alat (1 tahun)

$=\left(89.000 \mathrm{~m}^{2} \times 0,3670128 \mathrm{tCO} 2 \mathrm{eq}\right.$

/ 90.000 t CO2eq) x Rp. 39.600 .000

$=$ Rp. 14.372.221,-

Dari perhitungan tersebut diketahui bahwa hutan mangrove pada ekowisata BJBR memberikan manfaat tidak langsung terhadap masyarakat sekitar hutan mangrove melalui penyerapan gas CO2 sebesar Rp.14.372.221,setiap tahun.

$\mathrm{CO} 2$ = Luas Mangrove x Rp. 14.372.221,-

$=700 \times$ Rp.14.372.221,-

$=$ Rp.10.060.554.700,-

Jadi bilamana tidak ada mangrove di ekowisata BJBR maka, diperlukandana sebesar Rp. 10.060.554.700 guna membangun pohon sintetis guna menyerap C O2 $90.000 \mathrm{t}$ $\mathrm{CO} 2$ eq dengan umur teknis 10 tahun.

\section{Nilai OV (Option Value)}

\section{Tanggul Alami}

Menurut [6], Manfaat lain dari adanya ekosistem hutan mangrove adalah perannya yang sangat penting sebagai tanggul alami yang berfungsi sebagai pemecah gelombang dan mencegah intrusi air laut. Mengingat jika tidak terdapat hutan mangrove maka diperlukan untuk membuat tanggul beton guna memecah gelombang dan pencegah intrusi air laut sehingga perlu biaya yang cukup besar yaitu sekitar Rp. 3.989.007,62,per meternya dengan umur teknis 10 tahun. Tanggul Alami :

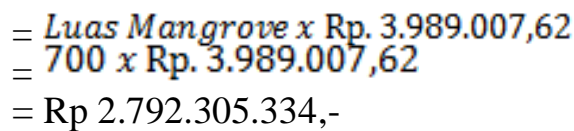

Jadi, bila tidak ada hutan mangrove yang menjadi ekowisata seluas $700 \mathrm{~m}^{2}$ maka Pemerintah Kota Probolinggo akan mengalami kerugian sebesar Rp. 2.792.305.334 sebab mangrove memiliki peranan sebagai pencegah intrusi air laut jawa serta pemecah gelombang laut [1].

\section{Nilai BV (Bequest Value)}

\section{Nilai Warisan Ekosistem Mangrove}

Menurut [9] bahwa nilai warisan diperoleh dari $10 \%$ nilai Direct Use Value (DUV), sehingga diperoleh nilai BV, sebesar : 10 \% X Rp. 960.000.000,- = Rp. 96.000.000,Analisa Valuasi Ekonomi Ekowisata Mangrove, dengan menggunakan metode TEV, dapat diperoleh sebagai berikut :

$\mathrm{TEV}=\mathrm{DUV}+\mathrm{IUV}+\mathrm{OV}+\mathrm{BV}$

= Rp. $(960.000 .000,-+10.060 .554 .700,-+$

2.792.305.334,- + 96.000.000,- )

= Rp. 13.908.860.034.000,-

\section{Dampak Sosial dan Ekonomi Ekowisata Terhadap Masyarakat Pesisir Pantai Mayangan, Selat Madura}

\section{Meningkatkan Kesempatan Kerja dan Menurunkan Tingkat Pengangguran di Kecamatan Mayangan, Selat Madura}

Dampak sosial ekonomi dari adanya sebuah ekowisata di suatu wilayah yakni akan memberikan kesempatan kerja yang tentu akan menekan tingkat pengangguran yang ada. Hal ini diperkuat oleh [5], yang mengatakan bahwa pariwisata mampu memberikan kesempatan kerja dan pekerjaan 
yang timbul tidak memerlukan pendidikan dan keterampilan. Berikut tabel 1 menyajikan tingkat pengangguran di Kota Probolinggo dan gambar 1 menampilkan diagram laju tingkat pengangguran.

Tabel 1. Laju Tingkat Pengangguran

\begin{tabular}{cc}
\hline Tahun ke & Indeks Tingkat Pengangguran \\
\hline 1 & 4,44 \\
2 & 4,34 \\
3 & 4,07 \\
\hline \multicolumn{2}{l}{ Sumber: Badan Pusat Statistik Kota Probolinggo, 2017 }
\end{tabular}

Dari tabel 1 yang menampilkan Laju Tingkat Pengangguran di Kota Probolinggo dapat dilihat indeks tingkat pengangguran mengalami penurunan mulai tahun ke $1-3$. Pada tahun ke 1 indeks tingkat pengagguran sebesar 4.44 dan turun pada tahun ke 2 dan tahun ke 3 berturut-turut sebesar 4,34 dan 4,07. Penurunan ini dapat disebabkan karena terbukanya lapangan pekerjaan baru di Kota Probolinggo terutama kawasan wisata Kota Probolinggo yang tentu juga membuka pintu bagi usaha lainnya [11].

\section{Dampak Ekonomi (Positif)}

\section{a) Tingkat Pendapatan Masyarakat Kecamatan Mayangan}

Penelitian ini dilakukan terhadap 51 responden, didapatkan data sebagai berikut: Tabel 2 berikut.

Tabel 2. Tingkat Pendapatan Sebelum (Before) Adanya Ekowisata

\begin{tabular}{ccc}
\hline $\begin{array}{c}\text { Pendapatan Sebelum } \\
\text { Ekowisata }\end{array}$ & $\begin{array}{c}\text { Jumlah } \\
\text { Responden }\end{array}$ & Presentase \\
\hline Rp. $<1.500 .000$ & 34 & $67 \%$ \\
Rp. $1.600 .000-$ Rp. & 11 & $22 \%$ \\
2.500 .000 & & \\
Rp. $\begin{array}{l}2.600 .000-\text { Rp. } \\
3.500 .000\end{array}$ & 6 & $12 \%$ \\
Rp. $>3.600 .000$ & 0 & $0 \%$ \\
\hline TOTAL & 51 & $100 \%$ \\
\hline Sumber: Data Primer yang Diolah, 2018 &
\end{tabular}

Sumber: Data Primer yang Diolah, 2018

Dari data dapat dilihat bahwa responden yang memiliki penghasil Rp. $<1.500 .000$ berjumlah 34 responden atau $67 \%$, sedangkan responden dengan Penghasilan Rp. 1.600.000Rp. 2.500.000 berjumlah 11 responden atau $22 \%$. Responden dengan pendapatan $\mathrm{Rp}$. 2.600.000- Rp. 3.500 .000 sebanyak 6 responden atau $12 \%$.

Selanjutnya didapatkan perubahan tingkat pendapatan yang diterima oleh masyarakat tersaji dalam tabel 3 berikut :

Tabel 3. Tingkat Pendapatan Setelah (After) Adanya Ekowisata

\begin{tabular}{ccc}
\hline $\begin{array}{c}\text { Pendapatan Setelah } \\
\text { Ekowisata }\end{array}$ & $\begin{array}{c}\text { Jumlah } \\
\text { Responden }\end{array}$ & Presentase \\
\hline Rp. $<1.500 .000$ & 16 & $31 \%$ \\
Rp. $1.600 .000-$ Rp. & 20 & $39 \%$ \\
2.500 .000 & & \\
Rp. $2.600 .000-$ Rp. & 12 & $24 \%$ \\
3.500 .000 & & \\
Rp. $>3.600 .000$ & 3 & $6 \%$ \\
\hline TOTAL & 51 & $100 \%$ \\
\hline
\end{tabular}

Sumber: Data Primer yang Diolah, 2018.

Dari tabel 2 dan 3, didapatkan perubahan pendapatan terhadap responden atara lain:

1. Responden dengan pendapatan Rp. $<1.500 .000$ sebelum adanya ekowisata berjumlah 34 responden, dan mengalami perubahan menjadi 16 responden semenjak adanya ekowisata konservasi mangrove.

2. Responden dengan besar pendapatan antara Rp. $\quad 1.600 .000-R p . \quad 2.500 .000$ sebelum adanya ekowisata berjumlah 11 responden, dan mengalami peningkatan mejadi 20 responden.

3. Responden dengan pendapatan Rp. 2.600.000-Rp. 3.500.000 sebelum adanya ekowisata berjumlah 6 responden dan mengalami perubahan menjadi 12 responden semenjak adanya ekowisata konservasi mangrove.

4. Responden dengan pendapatan Rp.> 3.600.000 sebelum adanya ekowisata berjumlah 0 responden dan mengalami perubahan menjadi 3 responden semenjak adanya ekowisata konservasi mangrove. 


\section{b) Menurunnya Penduduk Miskin di Kecamatan Mayangan}

Dengan turunnya indeks laju pengangguran yang ditampilkan pada tabel 4 berikut, tentu akan memberikan dampak lain berupa berkurangnya jumlah penduduk miskin di Kota Probolinggo. Pada tabel berikut, akan menyajikan presentase penduduk miskin di Kota Probolinggo.

Tabel 4. Presentase Penduduk Miskin di Kota Probolinggo

\begin{tabular}{cc}
\hline Tahun ke & Presentase Penduduk Miskin \\
\hline 1 & 10,92 \\
2 & 9,55 \\
3 & 8,67 \\
\hline
\end{tabular}

Sumber: Badan Pusat Statistik Kota Probolinggo, 2017

Dari tabel diatas yang menyajikan prosentase penduduk miskin di Kota Probolinggo, yang mengalami penurunan semenjak tahun ke 1 hingga tahun ke 3 . Presentase penduduk miskin menurun dari 10,92 menjadi 8,67 pada tahun 2017.

\section{c) Habitat Berbagai Macam Fauna}

Menurut [2]. Ekosistem hutan mangrove dapat menjadi tempat bersarang, tempat memijah (spawning), tempat pembesaran (growing), dan tempat untuk mencari makan (feeding) baik habitat tetap ataupun habitat sementara dari berbagai macam fauna yang ada. Beberapa fauna yang memanfaatkan ekosistem hutan mangrove antara lain burung, udang, kepiting, kerang, teritip, tiram, polichaeta dan ikan. Hubungan timbal balik (simbiosis) antara fauna-fauna tersebut dengan ekosistem hutan mangrove ada yang bersifat saling menguntungkan (simbiosis mutualisme) dan ada juga yang bersifat merugikan bagi ekosistem hutan mangrove (simbiosis parasitisme). Contoh fauna yang bersifat saling menguntungkan dengan ekosistem hutan mangrove (simbiosis mutualisme) adalah Kepiting Bakau dan Kepiting Uca, hal tersebut dikarenakan Kepiting Bakau dan Kepiting Uca. memiliki peran untuk mendaur ulang materi organik pada ekosistem tersebut. Sementara itu, contoh fauna yang bersifat merugikan ekosistem hutan mangrove (parasitisme) adalah Tiram Crassostera yang menyebabkan terhambatnya pertumbuhan batang mangrove [2].

\section{KESIMPULAN DAN SARAN}

\section{Kesimpulan}

Dari penelitian berjudul Analisa Valuasi Ekonomi Ekowisata Mangrove di Pantai Mayangan, Selat Madura yang telah dilakukan, didapatkan kesimpulan antara lain

1. Ekowisata konservasi mangrove Bee Jay Bakau Resort (BJBR) Mereka tergerak untuk merubah sampah menjadi emas yang mana memiliki pengertian mengubah daerah yang dulunya terkenal kumuh dan kotor menjadi daerah yang bernilai ekonomi. Ekowisata ini dibuka pada tahun 2012 di lahan 8,9 Ha milik Pemerintah Kota Probolinggo. Visi dari ekowisata ini adalah merubah sampah menjadi emas.

2. Didapatkan Nilai Valuasi Ekonomi :

a. Modal Investasi:

Rp. 507.000.000,-

b. Biaya Total:

Rp. 667.642.000,-

c. Penerimaan: Rp. 900.000.000,-

d. $\mathrm{R} / \mathrm{C}$ ratio: 1,437

e.Keuntungan:Rp.285.049.050,-

f. BEP : Rp. 614.695.276,-

g. Rentabilitas: $44 \%$.

h. Nilai Valuasi Ekonomi dengan Model Total Economic Value sebagai berikut :

$\mathrm{TEV}=\mathrm{DUV}+\mathrm{IUV}+\mathrm{OV}+\mathrm{BV}$

$=$ Rp. $(960.000 .000,-+0.060 .554 .700$,-

$+2.792 .305 .334,-+96.000 .000,-$ )

$=$ Rp. 13.908.860.034.000,-

3. Diperoleh dampak positif sosial ekonomi antara lain:

a) Memberikan lapangan pekerjaan bagi masyarakat, hal ini dapat dilihat dengan turunnya tingkat pengangguran terbuka di Kota Probolinggo sejak tahun ke 1 hinngga 3. 
b) Berkurangnya penduduk miskin di Kota Probolinggo yang dapat dilihat dari Presentase penduduk miskin sejak tahun ke 1 hingga tahun ke 3 mengalami penurunan.

c) Peningkatan pendapatan yang diterima oleh masyarakat sekitar ekowisata konservasi mangrove.

d) Mangrove diperbaiki sehingga membuat ekosistem flora dan fauna di ekowisata mangrove menjadi lebih banyak.

\section{Saran}

Saran yang diberikan peneliti untuk manfaat kedepannya sebagai berikut:

1. Kepada pemerintah, diharapkan mampu pengetahuan kepada masyarakat dengan cara memberikan penyuluhan maupun insentif ekonomi agar masyarakat lebih memperhatikan kondisi lingkungan sekitar serta masyarakat lebih berperan aktif dalam menjaga kondisi lingkungan sekitar.

2. Kepada peneliti selanjutnya, diharapkan mampu melakukan penelitian yang lebih mendalam seperti kelayakan usaha, tingkat kepuasan konsumen maupun pengelolahan sampah menjadi tenaga alternatif (PLTSa).

3. Kepada masyarakat agar mampu mejaga kebersihan lingkungan sekitar dengan cara kerja bakti tiap 1 bulan sekali maupun kegiatan sosial lainnya.

4. Diharapkan kepada investor selaku pengelola ekowisata konservasi mangrove Bee Jay Bakau Resort juga mampu memberikan beberapa sosialisasi terhadap masyarakat sekitar akan pentingnya mangrove dengan melakukan kerjasama bersama Pemerintah Kota Probolinggo.

5. Kepada wiatawan dianjurkan untuk mematuhi peraturan yang ada, agar konservasi mangrove berkelanjutan atau sustainable.

\section{UCAPAN TERIMAKASIH}

Penulis mengucapkan terimakasih kepada DIKTI atas bantuan dana pada penelitian kami pada program PDUPT, dan kepada Rektor UB Bapak Prof. Dr. Ir. Nuhfil Hanani, MS, juga kepada Dekan FPIK-UB Bapak Prof.Dr. Ir. Happy Nursyam, MS. Serta kepada semua pihak yang telah membantu kami baik secara langsung maupun tidak langsung, sampai dengan terselesaikannya penulisan artikel ini.

\section{DAFTRA PUSTAKA}

[1] Anderies J.M., Janssen M.A., Ostrom E., 2004. A framework to analyze the robustness of socialecological systems from an institutional perspective. Ecology and Society 9(1): 18. [online] URL: http://www.ecologyandsociety.org/vol9 /iss1/art18. Diakses pada tanggal 10 April 2017 Pukul 18.00 WIB

[2] Azhari, R. F. 2014. Skripsi Pengembangan Usaha Pengolahan Produk Perikanan di Kecamatan Kademangan Kota Probolinggo, Jawa Timur (Studi Kasus Pada Usaha Kecil Menengah (UKM) Trisna Mandiri Binaan Dinas Kelautan dan Perikanan Kota Probolinggo). Malang. Tidak Dipublikasi.

[3] Budhisantoso, 1992. Pendidikan Indonesia Berakar Pada Kebudayaan Nasional, Konvensi Nasional Pendidikan Indonesia II, Meda. IKIP Medan.

[4] Dharma, S. 2008. Pengelolahan dan Analisis Data Penelitian. Direktorat Tenaga Kependidikan. Jakarta.

[5] Erawan, I. Nyoman. 1997. Perencanaan Pariwisata dalam perekonomian Bali : Efek Pengadaan Pengeluaran Wisatawan Terhadap Pendapatan Masyarakat. UGM. Yogyakarta. 
[6] Fauzi. 2000. Valuasi Ekonomi Ekosistem Terumbu Karang di Perairan Pulau Menjangan Provinsi Bali. Institut Pertanian Bogor. Bogor. Fadrika, T.M, Rahmawaty dan Harahap, Z.A. 2013. Kajian Potensi Untuk Ekowisata di Pantai Lestari Indah Kabupaten Serdang Bedagai Sumatera Utara. Fakultas Pertanian. Universitas Sumatera Utara.

[7] Fadrika, T.M. Rahmawaty dan Harahap, Z.A. 2013. Kajian Potensi Untuk Ekowisata di Pantai Lestari Indah Kabupaten Serdang Bedagai Sumatera Utara. Fakultas Pertanian. USU.

[8] Febriansyah, D. 2017. Total Value Economic Mangrove. Tidak dipublikasi. Malang

[9] Haslinah Y.N.I dan Hasmin. 2012. Valuasi Ekonomi Ekosistem Terumbu Karang Di Taman Wisata Perairan Kapoposang Kabupaten Pangkep. Universitas Hasanudin Makasar.

[10] Novanza, Primyastanto, M., dan Handayani, W. 2017. Dampak Ekowisata Konservasi Mangrove terhadap Sosial Ekonomi Masyarakat Pesisir Kecamatan Mayangan, Kota Probolinggo, Jawa timur. Skripsi. FPIK-UB. Tidak dipublikasikan. Malang

[11] Primyastanto, M., Dewi, R. Prita., E. Susilo, 2010. Perilaku Perusakan Lingkungan Masyarakat Pesisir Dalam Perspektif Islam. Malang. Jurnal PAL Pembangunan dan Alam Lestari vol. 1 no. 1 tahun 2010.

[12] Primyastanto, M., 2011. Feasibility Study Usaha Perikanan. FPIK-UB. Universitas Brawijaya. UB Press: Malang.
[13] Primyastanto, M., 2012. Policy (Kebijakan) Pengelolaan SDI (Sumber Daya Ikan)Pada Perikanan Over Fishing (Lebih Tangkap). UB Press: Malang.

[14] Primyastanto, M., A., Efani. Soemarno dan S. Muhammad. 2013. Faktor Yang Beperngaruh Terhadap Pendapatan dan Pengeluaran Nelayan Payang Jurung Di Selat Madura. Jurnal Ilmiah. FPIK. Universitas Brawijaya. Malang.

[15] Primyastanto, M., 2014. Pengembangan Model Ekonomi Rumah Tangga Nelayan Payang Dengan Pemberdayaan Kearifan Lokal Di Selat Madura. Disertasi. Universitas Brawijaya. Malang.

[16] Primyastanto, M., N. Harahab, A. Sartimbul dan D. S. Anggreani., 2015a. Studi Kelayakan Usaha Penggemukan Kepiting Bakau DI Kabupaten Gresik, Jawa Timur. Junal Ilmiah. FPIK. Universitas Brawijaya. Malang.

[17] Primyastanto, M., 2015b.Ekonomi Perikanan Kajian Pemberdayaan Masyarakat Pesisir Berbasis Teknologi Tepat Guna. Intelegensia Media. Malang.

[18] Primyastanto, M., 2017.IlmuKelautan dan Perikanan. Kebijakan Pembangunan dan Pengelolaan Sumberdaya Perikanan dan Kelautan. Penerbit Intrans Media. ISBN : 978979-3580-99-9

[19] Suparmoko, M. 2014. Valuasi Ekonomi Sumberdaya Alam dan Lingkungan. BPFE-Yogyakarta 